\begin{abstract}
Iranica
Abstracta Iranica Revue bibliographique pour le domaine irano-aryen

Volume 34-35-36 | 2017

Comptes rendus des publications de 2011-2013
\end{abstract}

\title{
Eleonora Pappalardo. Nisa parthica. I rhyta ellenistici
}

\section{Barbara Kaim}

\section{(2) OpenEdition}

\section{Journals}

\section{Édition électronique}

URL : http://journals.openedition.org/abstractairanica/42038

DOI : 10.4000/abstractairanica.42038

ISSN : 1961-960X

Éditeur :

CNRS (UMR 7528 Mondes iraniens et indiens), Éditions de l'IFRI

\section{Référence électronique}

Barbara Kaim, « Eleonora Pappalardo. Nisa parthica. I rhyta ellenistici », Abstracta Iranica [En ligne], Volume 34-35-36 | 2017, document 4, mis en ligne le 30 juillet 2017, consulté le 27 septembre 2020 URL : http://journals.openedition.org/abstractairanica/42038 ; DOI : https://doi.org/10.4000/ abstractairanica. 42038

Ce document a été généré automatiquement le 27 septembre 2020.

Tous droits réservés 


\title{
Eleonora Pappalardo. Nisa parthica. I rhyta ellenistici
}

\author{
Barbara Kaim
}

\section{RÉFÉRENCE}

Eleonora Pappalardo. Nisa parthica. I rhyta ellenistici. Firenze, La Lettere, 2010, 331 p., 234 pl., bibliographie. (Centro ricerche archeologiche e scavi di Torino per il Medio Oriente e l'Asia. Missione in Turkmenistan III)

1 En 1948-49 les archéologues soviétiques mettaient au jour sur le site de Vieille Nisa dans le bâtiment appelé d'après son plan "la maison carrée", une collection unique de 55 rhytons/rhyta en ivoire. Ces pièces firent l'objet d'une publication en russe par M. E. Masson et G. A. Pugacenkova (Parfianskie ritony Nisy, Askhabad - Moscou, 1956-1959), traduite en anglais (The Parthian Rythons of Nisa, Firenze 1982 = Monografie di Mesopotamia, vol. 1). La nouvelle publication de rhytons de Nisa apporte une contribution importante à la connaissance de l'art parthe et hellénistique ainsi qu'à la civilisation de l'Asie Centrale. Les deux premiers chapitres (l'introduction et la description de 48 rythons, 70 fragments et 8 terminaux) sont suivis de l'analyse de l'iconographie des frises sculptées sur ces rhytons. L'A. a distingué huit groupes thématiques. L'évidente centralité des sujets dionysiaques est dans la ligne du contexte rituel et funéraire dans lequel les rhytons ont été utilisés. À la suite de l'analyse stylistique des scènes et motifs représentés sur les rhytons l'A., conclut au manque d'homogénéité du style (elle distingue 8 huit groupes stylistiques) et une certaine répétitivité iconographique et thématique. Selon L'A., les rhytons ont été produits à Nisa par différents groupes d'artisans et leurs décorations peuvent être considérées comme une manifestation de l'art "proto-parthe" et en même temps que de l'art de cour des Arsacides. 


\section{AUTEURS}

BARBARA KAIM

Université de Varsovie 